\title{
Editorial Message: Special Section on Fuzzy Theory and Its Applications
}

\author{
Ching-Chih Tsai ${ }^{1} \cdot$ Chia-Feng Juang ${ }^{1}$
}

Published online: 28 August 2015

(C) Taiwan Fuzzy Systems Association and Springer-Verlag Berlin Heidelberg 2015

As the guest editors of the special section on fuzzy theory and its applications, we are very pleased to express short remarks on this very section, which is aimed to publish the latest, innovative, and outstanding research results in the International Journal of Fuzzy Systems (IJFS) in a very short review period. This section was called for participation in the 2014 international conference on fuzzy theory and its applications (iFUZZY 2014) held in Kaohsiung, Taiwan, over November 26-28, 2014, and 13 papers were submitted to the special IJFS session. They were initially reviewed and accepted as the oral presentations by the two guest editors. By following the rigorous paper review procedure of IJFS, we invited four IJFS associate editors, Prof. Shun-Feng Su (the current Editor-in-Chief of IJFS), Prof. Chin-Wang Tao, Prof. Chia-Feng Juang, and Prof. Ching-Chih Tsai, as the referees to raise questions and make comments for all the oral presentations in iFUZZY 2014. No-show papers are automatically rejected for possible publication in this special section. Based on the three review criteria on technical contributions, novelty, and completeness, six papers were provisionally accepted and asked for quality improvements according to the reviewers' comments and suggestions. These six papers have finally been accepted for publication in the IJFS special section on fuzzy theory and its applications after substantial and detailed revisions.
By looking into presented contents of these six papers in the special section, we are very delightful to make brief introductions to their contributions and novelty on fuzzy theory and its applications. These articles provide new, interesting, and timely useful results covering L-E-fuzzy lattices, fuzzy inference-enhanced VC-DRSA model for technical analysis in investment decision aid, optimal fuzzy controller design using an evolutionary strategy based on particle swarm optimization for redundant wheeled robots, improving mobile commerce adoption using a new hybrid fuzzy MADM model, performance of soft computing controllers in hemodialysis machines, and a fuzzy-neural adaptive terminal iterative learning control for fed-batch fermentation processes. All the six papers are collected together in the current issue in order to illustrate the main technical achievements of the 2014 IJFS special session in iFUZZY 2014. Last but not least, this editorial message not only delineates the paper submission, rigorous review, and quality assurance of the 2014 IJFS special session papers in detail, but also significantly encourages your kind paper submissions to the 2015 IJFS special session in iFUZZY 2015. We look forward to receiving your paper submissions this year.

Guest Editors, 2014 IJFS special section on fuzzy theory and its applications

\footnotetext{
Ching-Chih Tsai

cctsai@dragon.nchu.edu.tw

1 National Chung Hsing University, Taichung, Taiwan
} 